Universidad de Lima

Facultad de Psicología

Carrera de Psicología

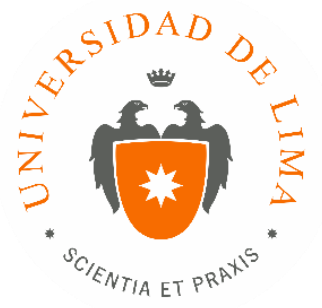

\title{
EXPERIENCIA EN EL TRABAJO CON NIÑOS QUE PRESENTAN CONDUCTAS DISRUPTIVAS EN UN CENTRO PSICOLÓGICO DE LIMA METROPOLITANA
}

Trabajo de suficiencia profesional para optar el título profesional de Licenciado en Psicología

\author{
Luciana Leyva Chanduví
}

Código 20052728

Lima - Perú

Febrero de 2019 


\section{EXPERIENCIA EN EL TRABAJO CON NIÑOS QUE PRESENTAN CONDUCTAS DISRUPTIVAS EN UN CENTRO PSICOLÓGICO DE LIMA METROPOLITANA}




\section{TABLA DE CONTENIDO}

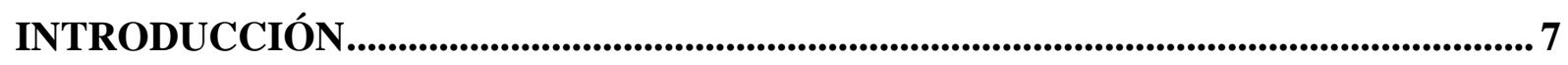

CAPÍTULO I: IDENTIFICACIÓN DEL PROBLEMA …….............................................. 8

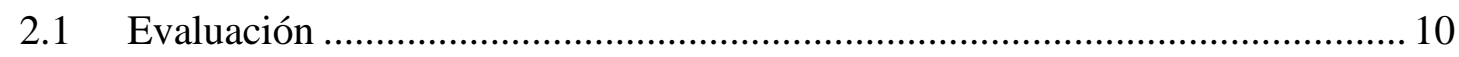

2.1.1 Obtención de información pertinente .................................................. 10

2.1.2 Observación del niño en diversos entornos .......................................... 11

2.1.3 Conceptualización del problema y desarrollo de la intervención 12

2.2 Programa de intervención terapéutica .............................................................. 13

2.2.1 Uso de técnicas operantes para la modificación de conducta................ 14

2.2.2 Actividades para una adecuada expresión y control de las

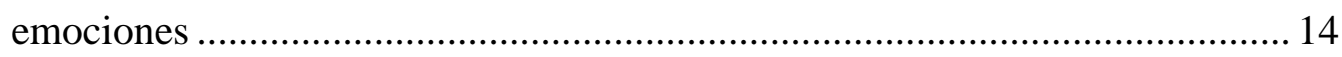

2.2.3 Actividades para que aprenda a controlar sus impulsos ........................ 15

2.2.4 Actividades para que el niño siga las normas básicas de

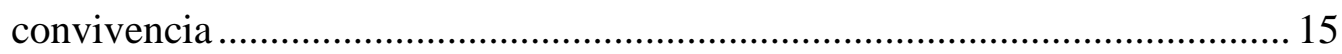

2.2.5 Actividades para explicar pensamiento-emoción-conducta .................. 16

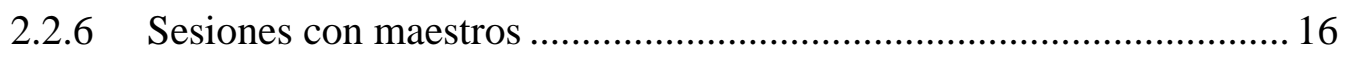

CAPÍTULO III: RESULTADOS DE LA INTERVENCIÓN.............................................17

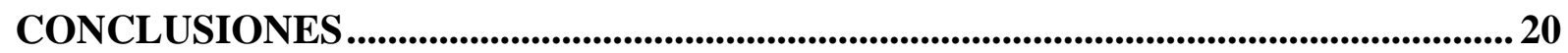

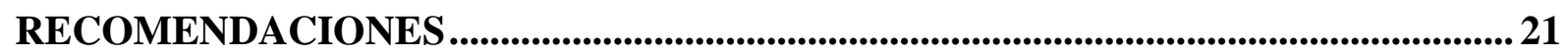

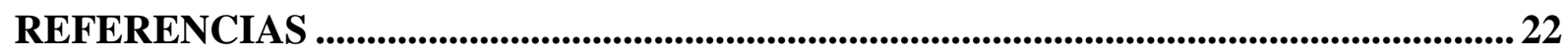

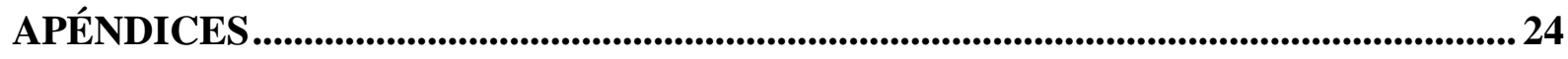




\section{ÍNDICE DE TABLAS}

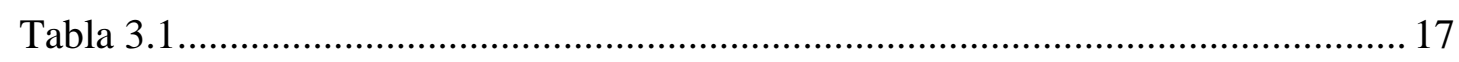

Porcentaje de reducción de la frecuencia de conductas impulsivas ............................ 17

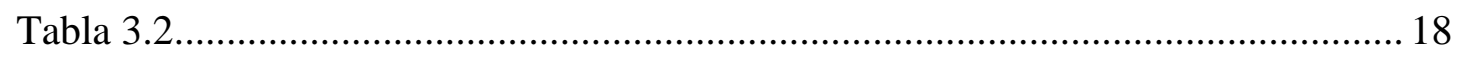

Porcentaje de reducción de la frecuencia de conductas agresivas .............................. 18

Porcentaje de aumento de la frecuencia de conductas más adaptativas..................... 19 


\section{ÍNDICE DE APÉNDICES}

APÉNDICE 1: Formato de Anamnesis................................................................... 25

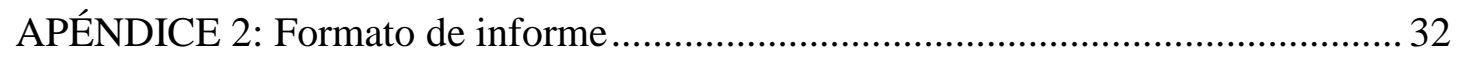

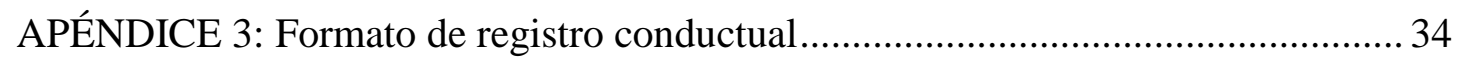

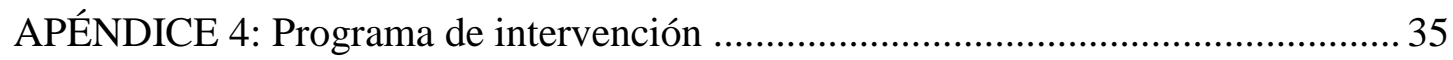




\section{INTRODUCCIÓN}

El rendimiento escolar preocupa a estudiantes, padres y maestros (Lamas, 2015) debido a que un bajo rendimiento significa que el niño no ha consolidado adecuadamente el aprendizaje esperado para su edad generando un retraso que podría llevarlo a la repitencia del año escolar. Las causas de este bajo rendimiento no están necesariamente relacionadas a problemas intelectuales, este puede deberse a que presenta conductas disruptivas en el aula que no le permiten adaptarse al contexto educativo (Vázquez, 2016) y por ende no cumple con los objetivos académicos. Es necesario plantear una intervención temprana para reducir el problema actual y sus futuras implicancias. El capítulo I describe el planteamiento del problema y fundamenta la necesidad de reducir las conductas disruptivas en el aula, principal causa del bajo rendimiento escolar de niños entre 08 y 10 años que llegan a un centro psicológico de Lima Metropolitana. El capítulo II describe las actividades realizadas para darle solución al problema antes planteado, haciendo una descripción detallada de las tareas realizadas. El capítulo III describe los resultados cuantitativos y cualitativos de la intervención. Por último, se presentan las conclusiones, recomendaciones y apéndices. 


\section{CAPÍTULO I: IDENTIFICACIÓN DEL PROBLEMA}

En Latinoamérica, el rendimiento escolar es una problemática que inquieta a estudiantes, profesores, padres y autoridades (Lamas, 2015). Se define rendimiento escolar como la medición de lo aprendido en el proceso educativo en base a los resultados de las actividades escolares realizadas (Osorio y Moreno, 2017). Prueba de esta inquietud es el Programa para la Evaluación Internacional de Alumnos (PISA), de la Organización para la Cooperación y el Desarrollo Económicos (OCDE), que evalúa las aptitudes de estudiantes en Ciencia, Matemática y Lectura en diferentes países con el fin de que los responsables de la educación planteen metas para mejorar la educación en su país. Si bien se aprecian mejoras en los resultados de los estudiantes peruanos en PISA 2015, esto resulta insuficiente debido a que gran parte de los estudiantes aún no han desarrollado las competencias antes mencionadas de manera satisfactoria (Ministerio de Educación, 2017). Estos resultados muestran que el rendimiento de los escolares peruanos está por debajo del promedio mundial.

El bajo rendimiento es una de las causas del fracaso escolar (pérdida de año o abandono escolar), el cual tiene consecuencias negativas a nivel personal y en el equilibro familiar, y a largo plazo puede afectar negativamente en la inserción laboral u ocasionar problemas sociales como la delincuencia (Solarte-Moreano, 2016). La OCDE señala que los problemas de conducta son uno de los tres obstáculos que afectan el aprovechamiento escolar. El bajo rendimiento de niños con problemas de conducta se debe a sus dificultades para adaptarse al contexto educativo más que a un problema intelectual (Vázquez, 2016). Las conductas disruptivas en el aula son patrones de descontrol conductual que desorganizan las actividades interpersonales del niño y del grupo al que este pertenece, teniendo dificultad para establecer relaciones saludables con sus pares y adultos (Armijos, 2016). 
Es necesaria la intervención temprana de estas conductas, no solo para disminuir el malestar generado en ese momento sino para prevenir problemas más severos a futuro (Vázquez, 2016). En el Registro Nacional de Trabajos de Investigación (Superintendencia Nacional de Educación Superior Universitaria, 2019) se puede apreciar que a nivel nacional se han implementado diversos programas para reducir estas conductas. Entre los más recientes se encuentran la investigación realizada por el Mg. Eduardo William Martínez Barrientos en 2018: “Programa 'pitufeando' en la disminución de las conductas disruptivas y en mejora de las habilidades motrices básicas, 2017” y la investigación de Bertha Petronila Carrillo Rueda del 2018: "Aplicación del programa de asertividad sobre las conductas disruptivas de los estudiantes de 5to grado de educación primaria de la Institución Educativa N ${ }^{\circ} 6060$ - Julio César Tello || del distrito Villa María del Triunfo.

En el contexto en el que algunas instituciones de educación básica regular particulares de Lima solicitan apoyo externo de psicólogos para el manejo de niños con bajo rendimiento debido a que presentan conductas disruptivas y problemas en el desarrollo, se crea el centro psicológico donde se llevó a cabo la experiencia laboral que se expondrá en el presente trabajo. El centro recibe casos con problemas de aprendizaje, de lenguaje, socioemocionales y de conducta. La población que suele recibir el centro se encuentra entre los 04 y 17 años de edad, derivados por instituciones de educación básica regular particulares de los distritos de San Miguel, Magdalena, Jesús María y Breña. El centro está conformado por la directora, dos psicólogas licenciadas, dos bachilleres y dos internas en Psicología. La directora supervisa todos los casos y atiende los más complejos. El centro tiene un enfoque cognitivo conductual y brinda los siguientes servicios: evaluación integral y conductual, terapia individual y grupal, y escuela para padres. A partir de la problemática antes descrita surge la pregunta: ¿De qué manera se puede ayudar a reducir las conductas disruptivas en el aula de niños entre 08 y 10 años que llegan a un centro psicológico de Lima Metropolitana y así mejorar su rendimiento escolar? 


\section{CAPÍTULO II: DESCRIPCIÓN DE LAS ACTIVIDADES Y}

\section{TAREAS REALIZADAS}

Frente al problema antes descrito se planteó un modelo de intervención psicológico cognitivo conductual dirigido a niños entre 08 y 10 años que llegaban a un centro psicológico de Lima Metropolitana para reducir sus conductas disruptivas en el aula, principal causa de su bajo rendimiento escolar. Primero se realizó la evaluación del problema para poderlo conceptualizar correctamente y proponer la intervención terapéutica más apropiada. El modelo de intervención se llevó a cabo con 06 niños y tuvo una duración de 06 meses.

\subsection{Evaluación}

La evaluación se realizó en 10 sesiones y tuvo como objetivo obtener información para conceptualizar el caso desde una perspectiva cognitivo conductual (McClure y Friedberg, 2011). Las técnicas más utilizadas en la evaluación conductual son: observación, registros de conducta y análisis funcional (Del Barrio, 2016).

\subsubsection{Obtención de información pertinente}

Se tuvo como objetivo tener un adecuado conocimiento de los problemas actuales y de la historia del niño (Sattler, 2009). Se realizó una entrevista de 60 minutos con los padres del niño. Primero se buscó completar los datos de filiación, para luego dejar que los padres expresaran cuál era el motivo de consulta. Enseguida se inició una entrevista semiestructurada tomando como guía la Anamnesis del centro (Apéndice1). Se hizo un análisis cronológico del desarrollo de los síntomas del problema, dónde, cuándo y con quién se 
daban y su intensidad y frecuencia. Para conocer las variables, se indagó sobre la historia del menor, el contexto, los antecedentes y consecuencias de las conductas problema (McClure y Friedberg, 2011). Luego se estableció el encuadre de la evaluación. Se llevaron a cabo dos sesiones de 45 minutos con el niño en donde se buscó establecer un adecuado rapport. En estas se utilizó el juego no estructurado para obtener información relevante para el caso mediante la observación no estructurada y el registro narrativo (Del Barrio, 2016). Además, se realizó una entrevista semiestructurada de 60 minutos con el niño acompañada de actividades lúdicas con el fin de conocer los componentes del caso. También se solicitó a los padres que firmen un consentimiento informado autorizando realizar entrevistas con el personal educativo. En la primera, con una duración de 60 minutos, participaron la psicóloga escolar, la bachiller y la directora del centro. Se indagó sobre su apreciación del problema, sus reacciones ante las conductas del niño, su relación con este, la relación del niño con sus pares, etc. Asimismo, se solicitaron informes psicoeducativos $\mathrm{y}$ registros conductuales para su análisis.

\subsubsection{Observación del niño en diversos entornos}

El objetivo fue obtener información sobre las conductas del niño. Se realizó una observación no estructurada en el centro educativo, con el fin de detectar conductas no evidenciadas por las fuentes de información. Una vez establecidas las conductas problema, se determinó cuándo, a quién, dónde y durante cuánto tiempo se realizaría la observación. Esta fue sistematizada y se llevó a cabo en días y momentos diferentes registrando las características 
observables de la conducta (frecuencias, duración e intervalo) (Del Barrio, 2016) y los antecedentes y consecuencias que influían en esta usando registros conductuales y matrices de interacción. La directora del centro también realizó observaciones para ver si había fiabilidad en los registros.

\subsubsection{Conceptualización del problema y desarrollo de la intervención}

Se tuvo como objetivo integrar la información obtenida para lograr conceptualizar el problema y proponer estrategias de intervención. Fue necesario integrar los datos obtenidos en las entrevistas y en los registros conductuales y funcionales con los resultados que figuraban en los informes de derivación. Se determinó que el bajo rendimiento escolar del niño tenía como principal causa su conducta disruptiva, siendo esta el problema manifiesto. Si bien cada niño presentaba problemas particulares, tenían conductas en común que se agruparon de la siguiente manera: conducta impulsiva (juega cuando se espera que no lo haga, se levanta de su silla cuando se espera que esté sentado, habla en momentos que no debería, interrumpe a los demás, coge las cosas de los demás sin pedir permiso y usa el llanto para solucionar sus problemas) y conductas agresivas (golpea y se burla de sus pares, insulta a sus compañeros o adultos y daña objetos de otras personas). Luego se determinaron los antecedentes que las generan y las consecuencias que las refuerzan. Se determinó cuáles eran los síntomas físicos, interpersonales, emocionales y cognitivos del problema manifiesto. Las causas del problema podían provenir por parte de los padres y maestros (estilos de crianza, reforzamiento de las conductas inadecuadas, poco interés en las conductas adecuadas del niño, etc.) o podían estar relacionadas a 
aspectos propios del menor (desarrollo, poco autocontrol, pocas habilidades sociales, etc.) (McClure y Friedberg, 2011). En base a esto, se determinó cuáles eran las técnicas por utilizar y el número de sesiones. Lo antes mencionado se trasmitió a los padres en una sesión de 45 minutos donde se entregó el informe (Apéndice 3), se absolvieron sus dudas y se encuadró la terapia. Se les explicó qué esperar del menor y qué aspectos del entorno debían ser modificados.

\subsection{Programa de intervención terapéutica}

El trabajo con el niño se realizó mediante un programa que tuvo una duración de 12 meses, dividido en 2 sesiones semanales de 45 minutos. Si bien el objetivo era lograr que el niño disminuya sus conductas disfuncionales, se dio énfasis en lograr que el niño adquiriera habilidades para realizar conductas más funcionales: adecuada expresión de las emociones, control de impulsos, conocimiento de la relación entre pensamiento, emoción y conducta y seguir normas básicas de convivencia. En toda sesión se enviaron tareas para casa y se les explicó a los padres lo trabajado. Asimismo, los padres tuvieron una sesión mensual de 45 minutos para discutir los avances y conductas del menor y aprender estrategias para manejar adecuadamente las conductas de sus hijos y potenciar sus fortalezas (Burge, Gomar y Mandil, 2009). A continuación, se explicarán las técnicas utilizadas basadas en los libros Terapia cognitiva con niños y adolescentes: Aportes técnicos (Burge et al., 2009) y Modificación de la conducta y sus aplicaciones prácticas (Kazdin, 2009). Estas técnicas se trabajaron con fichas y material didáctico (dibujos, videos, cuentos, juego de roles y de mesa). 


\subsubsection{Uso de técnicas operantes para la modificación de conducta}

El objetivo fue disminuir las conductas disfuncionales y desarrollar conductas más adaptativas. Para la disminución de las conductas disruptivas se utilizó reforzamiento de conductas incompatibles, sobrecorrección y extinción. Las conductas adaptativas se desarrollaron con modelado, moldeado dividiendo en pasos la conducta, reforzamiento positivo, instrucciones verbales, economía de fichas y contratos de contingencia (Kazdin, 2009). Previamente se eligieron los reforzadores a usar tomando en cuenta los gustos del niño. Las técnicas se usaron en todas las sesiones y también fueron explicadas a los padres para que las usaran en casa.

\subsubsection{Actividades para una adecuada expresión y control de las emociones}

El objetivo fue lograr que el niño tenga una adecuada expresión de sus emociones. Se buscó que desarrolle un vocabulario emocional, identifique las emociones básicas, reconozca qué situaciones las generan y cuáles son los síntomas físicos y conductuales que las acompañan. Luego se trabajó el control emocional mediante el "termómetro emocional", el cual tiene una numeración del 1 al 10, siendo la zona del 7 al 10 la "zona del descontrol”. Se le enseñó las consecuencias de llegar al 10 y se buscó que el niño reconozca las señales de alarma previas al descontrol y aprenda a manejarlas usando técnicas relajantes como cantar, apretar fuertemente su almohada, dibujar, pensamientos positivos, etc. (Burge et al., 2009). Lo antes mencionado se trabajó con dados, cartas y ruletas emocionales, videos, entrenamiento en autoinstrucciones y autorregistros. 


\subsubsection{Actividades para que aprenda a controlar sus impulsos}

El objetivo fue lograr que el niño tenga un adecuado control de su conducta. Mediante la metáfora del "mundo feliz", se le explicó que hay conductas que hacen al mundo feliz y otras que lo entristecen. Luego se le pidió que reconozca cuáles son estas conductas de acuerdo a las consecuencias que estas generan en ellos y en los demás. Asimismo, se usó la técnica de las cadenas de conducta, en la cual el niño dibuja su conducta inadecuada, el antecedente y la consecuencia de esta, luego se pegan los dibujos formando una cadena. En ambos casos se buscó que el niño se haga responsable de sus conductas y comprenda cómo estas lo afectan y afectan a los demás, y encuentre modos más adaptativos de resolver sus conflictos. Asimismo, se utilizó la técnica del semáforo conductual para lograr que el niño se detenga antes de actuar (rojo), piense en las consecuencias de sus actos (amarillo) y realice la conducta más adaptativa (verde).

\subsubsection{Actividades para que el niño siga las normas básicas de convivencia}

El objetivo fue lograr que el niño aprenda normas de convivencia. Se determinaron cuáles son estas y mediante videos, cuentos y muñecos, se buscó modelar la conducta, la que posteriormente se reforzó socialmente. Asimismo, se utilizó economía de fichas con cuatro conductas como máximo. El premio que recibía el niño al cumplirlas dependía de cuantas de estas realizaba (Kazdin, 2009). Se trabajó la comunicación asertiva, usando el cuento del dragón (comunicación agresiva), la tortuga (comunicación pasiva) y el niño (comunicación asertiva). 


\subsubsection{Actividades para explicar pensamiento-emoción-conducta}

El objetivo fue que el niño reconozca la relación entre pensamiento, emoción y conducta, para que logre reestructurar sus pensamientos desadaptativos. Primero se buscó que el niño sepa diferenciar entre pensamiento, conducta y emoción y luego que entendiera la relación entre estos. Luego se le entrenó en detectar pensamientos funcionales y disfuncionales frente a determinadas situaciones; esto mediante dibujos de viñetas con globos de pensamiento vacíos para que el niño complete, y autorregistros. Dependiendo del caso, se trabajaron los errores de pensamiento. Se trabajó la reestructuración cognitiva de los pensamientos desadaptativos del menor, se usó la autoverbalización positiva, autorregistros, autoinstrucción, juegos de roles, etc. (Burge et al., 2009).

\subsubsection{Sesiones con maestros}

Estas sesiones tenían como objetivo lograr un trabajo coordinado con el colegio para tener mayores resultados en el programa de intervención (Burge et al., 2009). La primera sesión se llevó a cabo al inicio del proceso terapéutico y participaron la tutora del aula y la psicóloga del colegio. En esta se explicaron las causas de los problemas de conducta en el aula y se les entregó y explicó recomendaciones para un mejor manejo de estas. Asimismo, se coordinó para que los maestros hicieran entrega de reportes semanales de conducta (Burge et al., 2009). Se realizaron sesiones al final de cada trimestre y se coordinó frecuentemente por correo o teléfono. 


\section{CAPÍTULO III: RESULTADOS DE LA INTERVENCIÓN}

Finalizados los 06 meses de la intervención, nuevamente se realizaron observaciones estructuradas en la escuela para determinar la frecuencia con que se presentaban las conductas problema. Estos resultados se compararon con los obtenidos al inicio de la intervención y se determinó en qué porcentaje había disminuido la frecuencia de dichas conductas en el niño. En la tabla 3.1, se ilustra cómo se redujo la frecuencia de las conductas impulsivas en los 06 casos. Se puede apreciar una reducción de más de $70 \%$ en la frecuencia con que se presenta la conducta. Esto gracias al uso de técnicas operantes y el desarrollo de conductas más adaptativas, propiciadas mediante las actividades de control de impulsos y de emociones. Se logró que los niños comprendieran que las conductas desadaptativas tienen consecuencias negativas y deben pensar en ellas antes de actuar. Esto les resultó más fácil de realizar en la relación con adultos que con niños de su edad.

Tabla 3.1

Porcentaje de reducción de la frecuencia de conductas impulsivas

\begin{tabular}{|c|c|c|c|c|c|c|}
\hline Paciente & $\begin{array}{l}\text { Juega cuando } \\
\text { se espera que } \\
\text { no lo haga }\end{array}$ & $\begin{array}{l}\text { Se levanta de } \\
\text { su silla } \\
\text { cuando se } \\
\text { espera que } \\
\text { esté sentado }\end{array}$ & $\begin{array}{l}\text { Habla en } \\
\text { momentos } \\
\text { que no } \\
\text { debería }\end{array}$ & $\begin{array}{l}\text { Interrumpe a } \\
\text { los demás }\end{array}$ & $\begin{array}{l}\text { Coge las } \\
\text { cosas de los } \\
\text { demás sin } \\
\text { pedir } \\
\text { permiso }\end{array}$ & $\begin{array}{l}\text { Usa el llanto } \\
\text { para } \\
\text { solucionar } \\
\text { sus } \\
\text { problemas }\end{array}$ \\
\hline Niño 1 & $80 \%$ & $90 \%$ & $79 \%$ & $89 \%$ & $90 \%$ & $70 \%$ \\
\hline Niño 2 & $90 \%$ & $100 \%$ & $80 \%$ & $84 \%$ & $99 \%$ & $80 \%$ \\
\hline Niño 3 & $70 \%$ & $82 \%$ & $70 \%$ & $82 \%$ & $90 \%$ & $70 \%$ \\
\hline Niño 4 & $90 \%$ & $78 \%$ & $90 \%$ & $92 \%$ & $96 \%$ & $85 \%$ \\
\hline Niño 5 & $79 \%$ & $90 \%$ & $85 \%$ & $90 \%$ & $100 \%$ & $79 \%$ \\
\hline Niño 6 & $99 \%$ & $100 \%$ & $80 \%$ & $88 \%$ & $100 \%$ & $88 \%$ \\
\hline
\end{tabular}

Elaboración propia.

En la tabla 3.2, se ilustra cómo se redujo la frecuencia de las conductas agresivas en los 06 casos. Se puede apreciar en todos los niños una reducción de estas conductas de más del $80 \%$. 
Se logró que los niños controlaran su ira y encontraran formas más adaptativas de expresar sus emociones y defenderse. Si bien los niños conocían estas formas, era difícil ponerlas en práctica con compañeros que no las presentaban.

Tabla 3.2

Porcentaje de reducción de la frecuencia de conductas agresivas

\begin{tabular}{lllll}
\hline Paciente & Golpea a sus pares & $\begin{array}{l}\text { Insulta a sus } \\
\text { compañeros o } \\
\text { adultos }\end{array}$ & $\begin{array}{l}\text { Se burla de sus } \\
\text { compañeros }\end{array}$ & $\begin{array}{l}\text { Daña objetos de } \\
\text { otras personas }\end{array}$ \\
\hline Niño 1 & $80 \%$ & $88 \%$ & $99 \%$ & $100 \%$ \\
Niño 2 & $90 \%$ & $100 \%$ & $100 \%$ & $100 \%$ \\
Niño 3 & $100 \%$ & $100 \%$ & $97 \%$ & $100 \%$ \\
Niño 4 & $99 \%$ & $80 \%$ & $98 \%$ & $100 \%$ \\
Niño 5 & $100 \%$ & $98 \%$ & $100 \%$ & $100 \%$ \\
Niño 6 & $100 \%$ & $100 \%$ & $100 \%$ & $100 \%$ \\
\hline Elaboración propia & & & &
\end{tabular}

La reducción de las conductas disfuncionales se dio primero en el espacio terapéutico, luego en el familiar y por último en el escolar. Asimismo, se apreció una reducción en la duración de las siguientes conductas: hablar en momentos que no debería y llorar y gritar para solucionar sus problemas. Cabe resaltar que esta última demoró más en reducirse en el ámbito familiar ya que a los padres se les dificultaba no reforzar dicha conducta. En la tabla 3.3, se ilustra cómo aumentó la frecuencia de conductas más adaptativas en los 06 casos. Se puede apreciar en todos los niños un aumento de más del 70\% en la frecuencia de la mayoría de las conductas. Una de las causas del bajo rendimiento era que no terminaban sus actividades por realizar conductas disruptivas. Aproximadamente al cuarto mes los niños culminaban las actividades planteadas en clase. A partir del tercer mes los niños manifestaron llevarse mejor con sus compañeros, cosa que no ocurría al inicio de la intervención debido a sus conductas agresivas y a que no tenían recursos para defenderse asertivamente. 


\section{Tabla 3.3}

Porcentaje de aumento de la frecuencia de conductas más adaptativas

\begin{tabular}{lllll}
\hline & $\begin{array}{l}\text { Usa palabras } \\
\text { mágicas }\end{array}$ & $\begin{array}{l}\text { Comparte con sus } \\
\text { pares }\end{array}$ & $\begin{array}{l}\text { Culmina las } \\
\text { actividades de } \\
\text { clase }\end{array}$ \\
\hline Niño 1 & $99 \%$ & $60 \%$ & $100 \%$ & $99 \%$ \\
Niño 2 & $100 \%$ & $70 \%$ & $100 \%$ & $97 \%$ \\
Niño 3 & $89 \%$ & $90 \%$ & $100 \%$ & $99 \%$ \\
Niño 4 & $97 \%$ & $89 \%$ & $100 \%$ & $100 \%$ \\
Niño 5 & $93 \%$ & $97 \%$ & $100 \%$ & $91 \%$ \\
Niño 6 & $98 \%$ & $100 \%$ & $100 \%$ & $92 \%$ \\
\hline
\end{tabular}

Elaboración propia

Por otro lado, se pudo apreciar en la boleta de notas, en los cuadernos y en lo que los padres y maestros indicaban, mejoras en las calificaciones de los niños a partir del cuarto mes aproximadamente. Las mejoras no se daban de una forma homogénea, cada niño mejoraba según sus características. Cuatro de los casos presentaban cursos desaprobados al inicio de la terapia, al finalizarla tenían sus cursos aprobados. Al inicio del programa, los niños recibían diariamente notificaciones de los docentes reportando sus conductas disruptivas, a partir del cuarto mes estas eran menos frecuentes y al finalizar el programa solo presentaban notificaciones de felicitación.

El modelo de intervención fue bien recibido por los padres, los cuales fueron constantes y participativos en todo el proceso. Gracias a que mediante el modelo de intervención se llegaron a reducir las conductas disruptivas de los 06 niños, lo cual contribuyó a que tuvieran un mejor rendimiento, la directora del centro determinó que este modelo de intervención sería utilizado para casos futuros por todo el personal del centro. Si bien se lograba coordinar las técnicas a utilizar con la tutora y profesores, en un inicio estos se mostraban un poco resistentes cuando se les recomendaba realizar alguna modificación en su proceder para optimizar la conducta del niño. No todos aplicaban las sugerencias que se les daba. 


\section{CONCLUSIONES}

- El modelo de intervención cognitivo conductual fue efectivo en la disminución de la frecuencia de las conductas disruptivas en los niños en el ámbito educativo.

- Esta disminución no se dio de la misma manera en todos los pacientes. En algunos casos se presentó la extinción de la conducta y en otros solo una disminución significativa.

- Los niños que redujeron la frecuencia de sus conductas disruptivas mejoraron su rendimiento escolar.

- La reducción de la frecuencia de las conductas impulsivas y agresivas se dieron con mayor rapidez y efectividad en su relación con sus padres y maestros ya que estos dejaron de reforzar las conductas disfuncionales, reforzando las más funcionales.

- La reducción de la frecuencia de las conductas impulsivas y agresivas hacia sus pares se dio con menos rapidez ya que muchos de sus compañeros presentaban conductas agresivas o impulsivas, situación que a los pacientes les costaba manejar.

- Una de las causas principales de las conductas disruptivas de los niños hace referencia a que los padres propiciaban y reforzaban dichas conductas, por lo que el trabajo con estos fue fundamental para la reducción de las conductas disfuncionales.

- Se realizó un trabajo coordinado con la escuela, sin embargo, muchos de los maestros se mostraban resistentes a que una persona externa a su centro de labores les sugiera cómo realizar su trabajo. Esto no contribuía con el proceso de cambio del menor. 


\section{RECOMENDACIONES}

A continuación, se detallarán las recomendaciones:

- Si bien, los resultados demuestran mejoras significativas en la reducción de la frecuencia de las conductas disruptivas, los niños deben seguir asistiendo a terapia una vez por semana para conseguir que los logros perduren en el tiempo y se extingan en su totalidad.

- Los niños deben asistir a terapias grupales donde se refuercen los temas abordados en la terapia individual con el fin de que logren aplicar con sus pares las conductas adaptativas recientemente adquiridas.

- Para garantizar que los padres adquieran estrategias para manejar adecuadamente las conductas de sus hijos y potenciar sus recursos y fortalezas, deben asistir a una escuela de padres semanal por el periodo de un mes.

- Proponer a las instituciones educativas capacitar a su personal docente en el manejo y prevención de conductas disruptivas. Asimismo, sugerir la implementación de programas de modificaciones de estas conductas en el aula, para que los maestros se encuentren más dispuestos al uso de estas técnicas.

- Si bien los casos fueron conceptualizados exitosamente, se debe implementar el uso de pruebas estandarizadas, válidas y confiables para tener más información. 


\section{REFERENCIAS}

Armijos Abad, M. A. (2016). Técnicas conductuales para disminuir las conductas disruptivas en los niños y niñas de quinto año paralelo A de la escuela de educación básica IV Centenario Nro. 2, sección vespertina, 2014-2015 (Tesis, previa a la obtención del grado de Licenciado en Ciencias de la Educación, Mención Psicología Educativa y Orientación, Universidad Nacional de Loja, Ecuador). Recuperada de http://dspace.unl.edu.ec/jspui/bitstream/123456789/16314/1/Marco\%20Antonio\%20 Armijos\%20Abad.pdf

Burge, E., Gomar, M. y Mandil, J. (2009). Terapia cognitiva con niños y adolescentes. Aportes técnicos (2. ${ }^{a}$ ed.). Buenos Aires: Librería Akadia Editorial.

Del Barrio Gándara, V. (2016). Evaluación Psicológica (2. ${ }^{a}$ ed.). Madrid: Centro Estudios Financieros.

Kazdin, A.E. (2009). Modificación de la conducta y sus aplicaciones prácticas (2. ${ }^{a}$ ed.). México D.F.: Editorial El Manual Moderno.

Lamas, H.A. (2015). Sobre el rendimiento escolar. Propósitos y Representaciones, 3(1), 313386. Recuperado de http://revistas.usil.edu.pe/index.php/pyr/article/view/74

McClure, J. M. y Friedberg, R.D. (2011). Práctica clínica de terapia cognitiva con niños y adolescentes: Conceptos esenciales. Barcelona: Grupo Planeta Spain.

Ministerio de Educación. (2017). El Perú en PISA 2015. Informe nacional de resultados [versión PDF]. Recuperado de http://umc.minedu.gob.pe/wpcontent/uploads/2017/04/Libro_PISA.pdf

Osorio León, F. M., y Moreno Pérez, J.E. (2017). Influencia de las técnicas de estudio innovadoras en la calidad del rendimiento escolar de los estudiantes del subnivel medio educación básica de la "Unidad Educativa Salitre" período 2017-2018. 
Propuesta: diseño de una guía didáctica con enfoque de destrezas con criterio de desempeño (tesis previo a la obtención del Título de Licenciadas en Ciencias de la Educación mención: Educación Primaria, Universidad de Guayaquil, Ecuador). Recuperada de http://repositorio.ug.edu.ec/handle/redug/24937

Sattler, J. M. (2009). Evaluación infantil: Fundamentos cognitivos (2. ${ }^{a}$ ed.). México D.F.: El Manual Moderno.

Solarte-Moreano, M. E. (2016). Disminución del bajo rendimiento y el fracaso escolar mediante la implementación de una escuela de padres y madres (tesis de maestría, Universidad Internacional de La Rioja, Colombia). Recuperada de https://reunir.unir.net/handle/123456789/4837

Superintendencia Nacional de Educación Superior Universitaria. (2019). Registro Nacional de Trabajos de Investigación. Recuperado de http://renati.sunedu.gob.pe/.

Vázquez Ramírez, M. A. (2016). Programas de desarrollo social/afectivo para alumnos con problemas de conducta. Manual para psicólogos y educadores [versión PDF]. Recuperado de http://www.infocoponline.es/pdf/PROBLEMASCONDUCTA.pdf 


\section{APÉNDICES}




\section{APÉNDICE 1: Formato de Anamnesis}

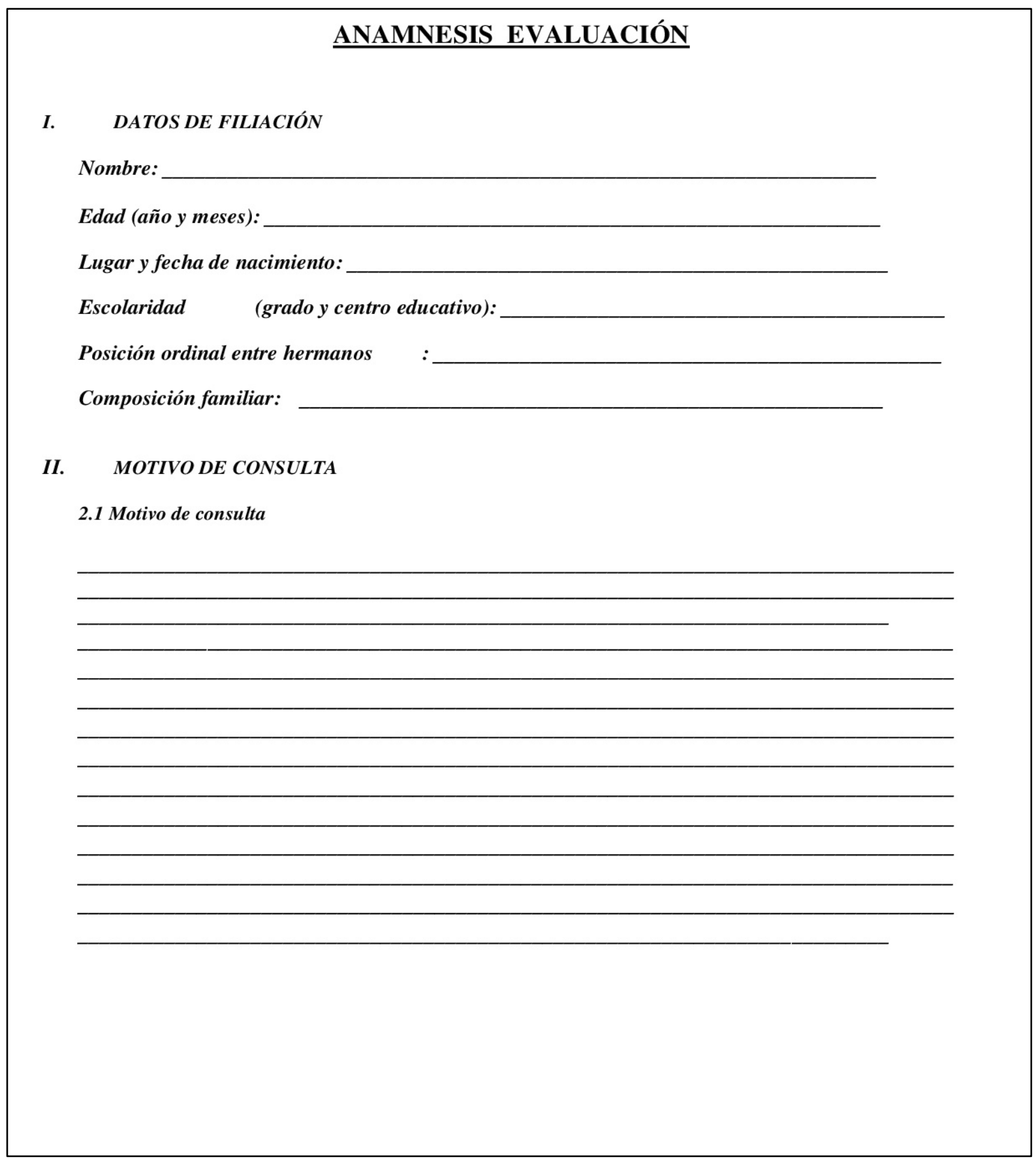


2.2 ¿Cómo se presentó esta dificultad? ¿Desde cuándo? ¿Quién lo detectó?

2.3 ¿Qué es lo que se ha intentado para solucionar este problema? Diagnóstico (si lo tuviera)

\subsection{Tratamiento recibidos ¿Cuánto tiempo? ¿En qué instituciones? Evolución del tratamiento}

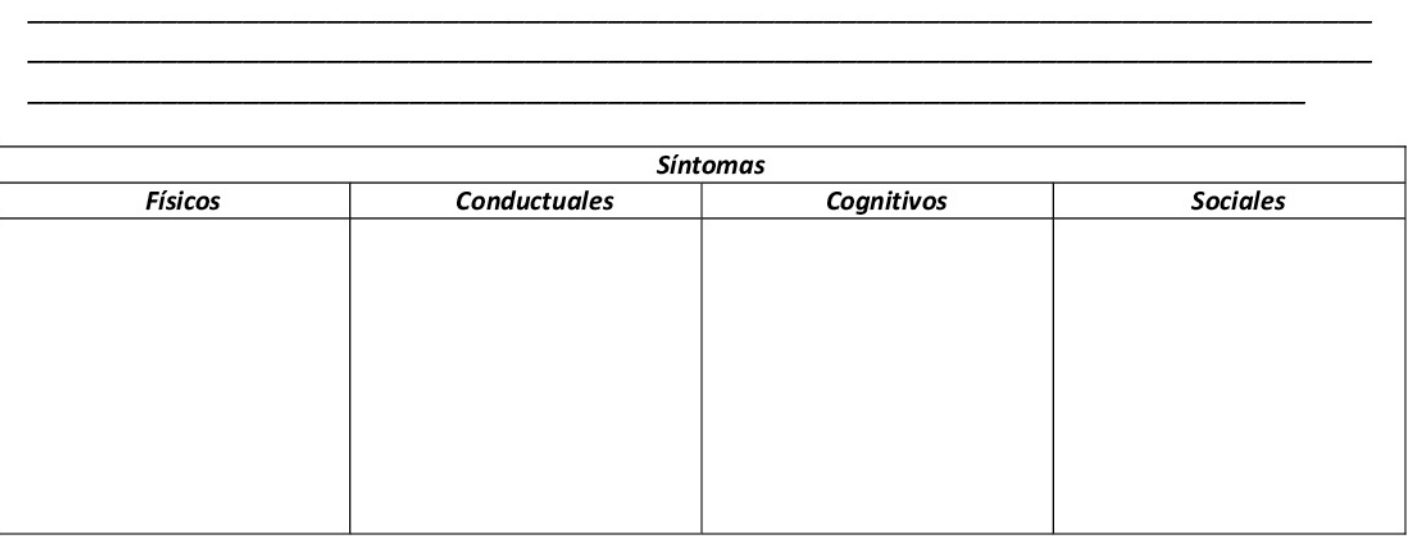

\begin{tabular}{|l|l|l|}
\hline \multicolumn{2}{|c|}{ Variables } \\
\hline Contexto & Predisposiciones & Antecedentes y consecuencias \\
\hline & & \\
& & \\
& & \\
\end{tabular}


III. HISTORIA EVOLUTIVA:

3.1. ¿Hubo algún incidente durante el embarazo, parto? ¿A qué tiempo nació?

3.2. Dificultades después del parto SI/NO

\section{HISTORIA MÉDICA:}

4.1. Estado de salud actual:

4.2. Principales enfermedades. Medicamentos consumidos:

4.3. Exámenes realizados (neurológico, audiológico, psiquiátrico, psicológico u otros).

Resultados:

\section{HISTORIA DEL DESARROLLO NEUROMUSCULAR}

5.1. Dificultades del desarrollo:

Levantar la cabeza $\square$, sentarse (sin ayuda) $\square$, gatear $\square$, pararse (sin ayuda $\square$ Caminar, $\square$ correr,

5.2. Dificultades, tendencia a caerse o golpearse SI / NO

5.3. Dominancia lateral manual. IZQUIERDA /DERECHA.

VI. HISTORIA DE LA HABILIDAD PARA HABLAR

• ¿Presenta dificultades en el lenguaje? ¿Las primeras palabras? ¿Cuándo?

- Habla demasiado, rápido
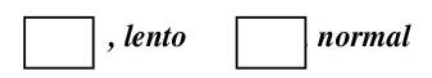


\section{HIGIENE}

- ¿A qué edad su hijo comenzó a controlar la orina? (diurna - nocturna)

- ¿Su hijo, pide cuando quiere hacer sus necesidades? SI / NO

• ¿Su hijo se asea solo? SI / NO. Si, requiere ayuda. ¿Cómo?

\section{SUEÑO}

-Sueño. Duración

$\longrightarrow u$

medicamentos (edad, frecuencia)

- Temores nocturnos.

- Otras dificultades,

Duerme acompañado o solo;

- ¿Se resiste a acostarse a un horario determinado? SI NO

\section{INDEPENDENCIA PERSONAL}

- ¿Su hijo ayuda en casa? ¿Qué hace? ¿Tiene responsabilidades, en el hogar? ¿Cómo manejan la disciplina?

- Disciplina en el hogar: existencia de normas, castigos y premios, quienes lo ejecutan. ¿Es constante?

- ¿Qué estilos de crianza emplea? ¿Hay discrepancia en estos criterios de crianza? ¿Quién más aplica los criterios de crianza? 
- Independencia para vestirse, atarse los zapatos, otros

X. CONDUCTA

¿Considera que su niño es ansioso?

¿Tolera la frustración?

¿Se adapta a situaciones nuevas?

¿Se come las uñas?

¿Se succiona los dedos?

SI NO

SI NO

- Carácter del niño

- Como se relaciona con sus hermanos

XI. JUEGO - RELACIONES SOCIALES

- ¿Su hijo juega solo? ¿Dirige o es dirigido? ¿Qué juegos prefiere? ¿Juega con niños de su edad, mayores o niños menores? Existen conductas de agresividad en el juego.

- ¿Utiliza videojuegos (celular, Tablet, televisor, computadora, consola)? ¿Desde hace cuánto tiempo?

- ¿Tiene su propio celular o usa el de los padres? ¿con qué frecuencia? 
- ¿Cómo son las relaciones con sus pares y adultos?

\section{HISTORIA EDUCATIVA}

- ¿Cómo le va en el colegio a nivel académico?

- Cambios en el colegio. Por qué?

- ¿Observó dificultades en el aprendizaje? ¿Desde cuándo? ¿Qué hizo?

- Repitencias. ¿Cuántas veces?

- Conducta en clases

Opinión del profesor.

\section{ANTECEDENTES FAMILIARES}

- Si /No. (Especificar enfermedades psiquiátricas, problemas del habla, dificultades en el aprendizaje, epilepsias, convulsiones, retardo

mental, otros). 


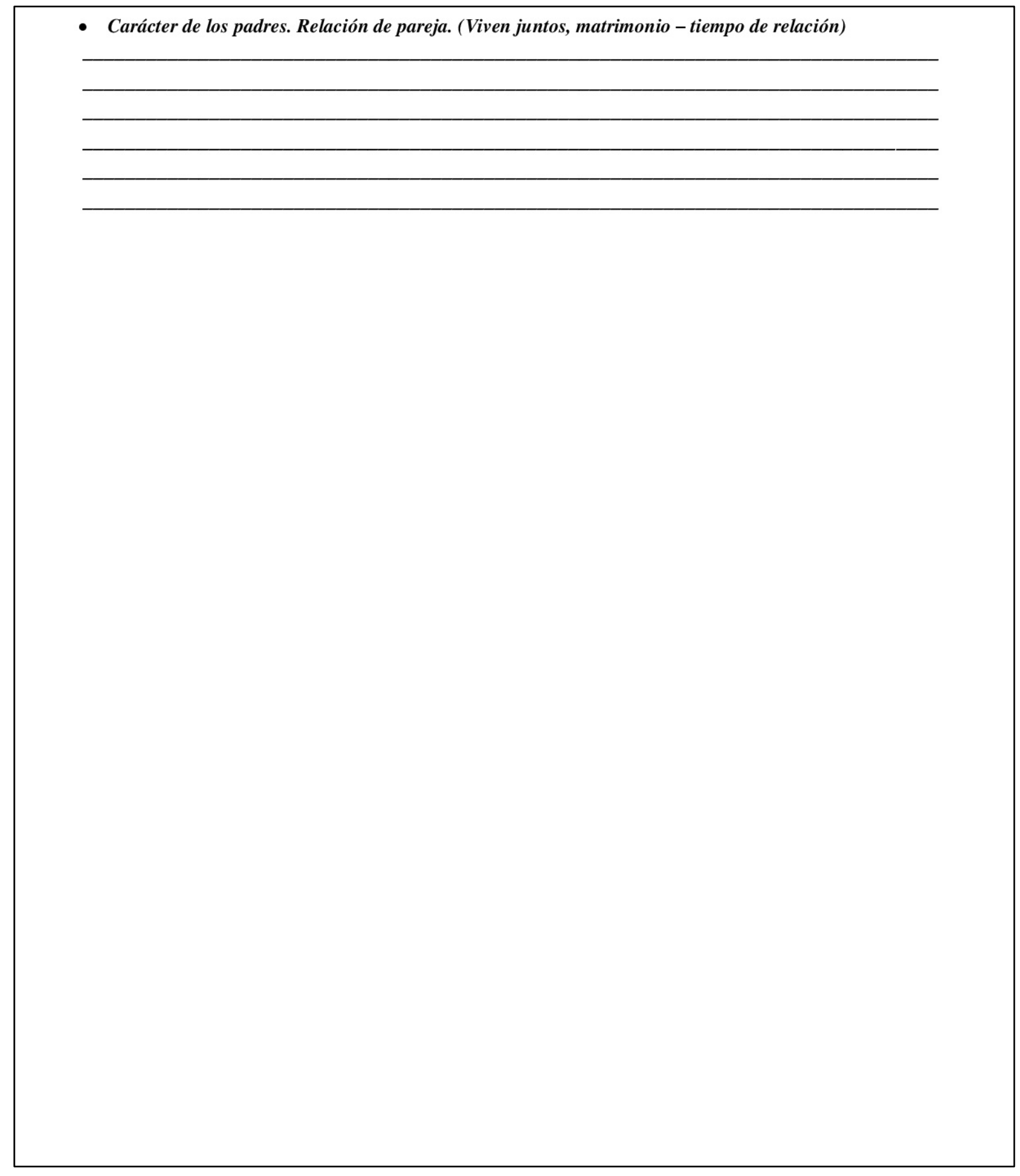




\section{APÉNDICE 2: Formato de informe}

\section{INFORME PSICOLÓGICO}

I. DATOS GENERALES

Apellidos y Nombres

Sexo

Edad

Fecha de Nacimiento

Centro educativo

Grado de instrucción

Fecha de evaluación

Fecha de informe

Examinadora

Psicóloga encargada

II. MOTIVO DE CONSULTA

II. ANTECEDENTES:

IV. OBSERVACIONES GENERALES Y DE CONDUCTA

V. TÉCNICAS UTHIZADAS

VI. RESULTADOS

- Nivel conductual.

- Nivel emocional.

- Nivel social.

- Nivel familiar.

- Nivel educativo. 


\begin{tabular}{|l}
\hline VII. CONCLUSIONES \\
VII. RECOMENDACIONES \\
\\
Para el niño: \\
Para los padres: \\
Para la escuela: \\
Para otros familiares: \\
\\
\\
\end{tabular}




\section{APÉNDICE 3: Formato de registro conductual}

\section{REGISTRO DE CONDUCTA EN EL RECREO}

Nombre:

Fecha:

Tiempo/ duración :

Personas presentes:

Observador:

\begin{tabular}{|l|l|l|l|l|}
\hline $\begin{array}{l}\text { Pegar a sus } \\
\text { compañeros. }\end{array}$ & & & & \\
\hline $\begin{array}{l}\text { Empujar a sus } \\
\text { compañeros. }\end{array}$ & & & & \\
\hline $\begin{array}{l}\text { Burlarse de sus } \\
\text { compañeros. }\end{array}$ & & & & \\
\hline $\begin{array}{l}\text { Quitarle las cosas } \\
\text { a sus pares sin } \\
\text { pedir permiso. }\end{array}$ & & & & \\
\hline
\end{tabular}




\section{APÉNDICE 4: Programa de intervención}

\section{PRESENTACIÓN DE CASO - PROGRAMA DE INTERVENCIÓN}

USO INTERNO

I. DATOS DE FILIACIÓN:

\section{Nombre}

Edad

Fecha de nacimiento

Lugar de nacimiento

$\mathbf{N}^{\circ}$ de hermanos

Grado de instrucción

Informante

Fecha

II. HISTORIA PERSONAL

- DESARROLLO INICIAL

- DESARROLLO PSICOMOTOR

- CONDUCTAS INADECUADAS EN LA PRIMERA INFANCIA

- SAlUd

- EDUCACIÓN

- RELACIONES INTERPERSONALES

- HISTORIA FAMILIAR

- MADRE

- PADRE

- HERMANOS

- OTROS FAMILIARES 
III. PROBLEMA ACTUAL

- MOTIVO DE CONSULTA

- OPINIÓN DEL PACIENTE SOBRE SU PROBLEMA

- DESARROLlo CRONOLÓgICO DE LOS SÍNTOMAS

- TRATAMIENTO PSICOLÓgICO Y/O PSIQUiÁtrico RECIBIDOS ANTERIORMENTE

- PROBLEMA MANIFIESTO

- LISTADO DE CONDUCTAS FUNCIONALES Y RECURSOS

- SINTOMAS

\begin{tabular}{|c|c|c|c|c|}
\hline \multicolumn{5}{|c|}{ SÍNTOMAS } \\
\hline Conductual & Emocional & Fisiológico & \begin{tabular}{|l|} 
Cognitivo \\
\end{tabular} & \begin{tabular}{|l} 
Interpersonal \\
\end{tabular} \\
\hline & & & & \\
\hline & & & & \\
\hline & & & & \\
\hline & & & & \\
\hline & & & & \\
\hline & & & & \\
\hline & & & & \\
\hline & & & & \\
\hline & & & & \\
\hline
\end{tabular}


IV. VARIABLES

- RESUMEN DE anÁlisis funcional de las conductas problema DISFUNCIONALES

\begin{tabular}{|l|l|l|}
\hline Antecedente & Conducta & Consecuencia \\
\hline & & \\
\hline & & \\
\hline & & \\
\hline & & \\
\hline & & \\
\hline & & \\
\hline & & \\
\hline & & \\
\hline
\end{tabular}

- CONTEXTO

- ESQUEMAS Y PREDISPOSICIÓN DEL NIÑO 
ESQUEMA DE PROGRRAMACION DE SESIONES

\begin{tabular}{|c|c|c|c|c|c|}
\hline Objetivo & Sesión & Actividades & $\begin{array}{l}\text { Técnicas } \\
\text { conductuales }\end{array}$ & Trabajo con padres & $\begin{array}{l}\text { Trabajo con la } \\
\text { tutora - } \\
\text { maestros }\end{array}$ \\
\hline $\begin{array}{l}\text { Lograr que } \\
\text { conozca las } \\
\text { reglas y } \\
\text { objetivos de la } \\
\text { terapia. }\end{array}$ & 1 & $\begin{array}{l}\text { Juegos de roles con } \\
\text { peluches para } \\
\text { comprender las } \\
\text { reglas } \\
\text { Fichas }\end{array}$ & $\begin{array}{l}\text { Instrucción } \\
\text { verbal. } \\
\text { Reforzamiento } \\
\text { positivo. } \\
\text { Moldeamiento } \\
\text { Economía de } \\
\text { fichas }\end{array}$ & $\begin{array}{l}\text { Se les explica cómo } \\
\text { generalizar estas reglas } \\
\text { en casa. }\end{array}$ & $\begin{array}{l}\text { Se les explica } \\
\text { cómo generalizar } \\
\text { estas reglas en el } \\
\text { aula. } \\
\text { Uso de economía } \\
\text { de fichas. }\end{array}$ \\
\hline \multirow{4}{*}{$\begin{array}{l}\text { Lograr que } \\
\text { identifique cuáles } \\
\text { son las reglas en } \\
\text { diferentes } \\
\text { espacios y la } \\
\text { importancia de } \\
\text { seguirlas. }\end{array}$} & 2 & $\begin{array}{l}\text { Identificar las reglas } \\
\text { y normas en } \\
\text { diferentes espacios: } \\
\text { casa, colegio, bus, } \\
\text { súper mercado, etc. }\end{array}$ & \multirow[t]{4}{*}{$\begin{array}{l}\text { Instrucción } \\
\text { verbal. } \\
\text { Reforzamiento } \\
\text { positivo } \\
\text { Moldeamiento }\end{array}$} & \multirow{4}{*}{\multicolumn{2}{|c|}{$\begin{array}{l}\text { - Pedir que realicen un listado de normas } \\
\text { que no sigue. } \\
\text { - Se les piden que llenen un registro de } \\
\text { análisis funcional. } \\
\text { Análisis funcional: se les explica cómo } \\
\text { sus conductas refuerzan conductas } \\
\text { disfuncionales. } \\
\text { - Se les explica qué aspectos del entorno } \\
\text { deben ser modificados para mejorar las } \\
\text { conductas del niño. Se les entrena o } \\
\text { explica el uso adecuado de técnicas } \\
\text { que desarrollen conductas deseadas } \\
\text { (modelado, moldeado, contratos } \\
\text { conductuales, economía de fichas, } \\
\text { etc.), que incrementen la frecuencia de } \\
\text { las conductas adaptativas del niño y } \\
\text { eliminen conductas disruptivas } \\
\text { (extinción, tiempo fuera, reforzamiento } \\
\text { de conductas incompatibles o de otras } \\
\text { conductas). } \\
\text { Se busca que sean el modelo de los } \\
\text { niños y realicen registros de análisis } \\
\text { funcional de la conducta de estos para } \\
\text { que dejen de reforzar conductas } \\
\text { inadecuadas y eviten antecedentes } \\
\text { desencadenantes de estas. } \\
\text { Asimismo, se busca que conozcan la } \\
\text { forma más óptima de dar instrucciones } \\
\text { y usen una disciplina positiva. Ponerle } \\
\text { límites claros y no reprocharlo con } \\
\text { tanta frecuencia. }\end{array}$}} \\
\hline & 3 & $\begin{array}{l}\text { Por qué es } \\
\text { importante seguir } \\
\text { las reglas. }\end{array}$ & & & \\
\hline & 4 & $\begin{array}{l}\text { Identificar las reglas } \\
\text { que incumple y las } \\
\text { consecuencias de } \\
\text { esto. }\end{array}$ & & & \\
\hline & 5 & $\begin{array}{l}\text { Buscar alternativas } \\
\text { a las reglas } \\
\text { incumplidas y } \\
\text { reflexionar sobre la } \\
\text { consecuencia. }\end{array}$ & & & \\
\hline \multirow{3}{*}{$\begin{array}{l}\text { Lograr que } \\
\text { comprenda que } \\
\text { todas sus } \\
\text { conductas tienen } \\
\text { consecuencias y } \\
\text { debe optar por } \\
\text { aquellas que sean } \\
\text { positivas. }\end{array}$} & 6 & $\begin{array}{l}\text { Mundo Feliz: } \\
\text { cuento y fichas. }\end{array}$ & \multirow{3}{*}{$\begin{array}{l}\text { Instrucción } \\
\text { verbal. } \\
\text { Reforzamiento } \\
\text { positivo. } \\
\text { Moldeamiento } \\
\text { RDI } \\
\text { Contrato de } \\
\text { contingencias. }\end{array}$} & \multirow{3}{*}{$\begin{array}{ll}\text { - } & \text { Repasar el } \\
\text { semáforo en casa. } \\
\text { - } & \text { Enseñar técnicas } \\
\text { operantes } \\
\text { relacionadas. } \\
\text { - Fomentar } \\
\text { disciplina }\end{array}$} & \multirow{3}{*}{$\begin{array}{l}\text { Explicar a la } \\
\text { maestra la } \\
\text { metáfora del } \\
\text { semáforo y } \\
\text { conseguir } \\
\text { que la use } \\
\text { con el niño. }\end{array}$} \\
\hline & 7 & $\begin{array}{l}\text { Mundo Feliz: fichas } \\
\text { y dibujos. }\end{array}$ & & & \\
\hline & 8 & $\begin{array}{l}\text { Cadena de } \\
\text { conductas y juego } \\
\text { de memoria con } \\
\text { tarjetas }\end{array}$ & & & \\
\hline
\end{tabular}




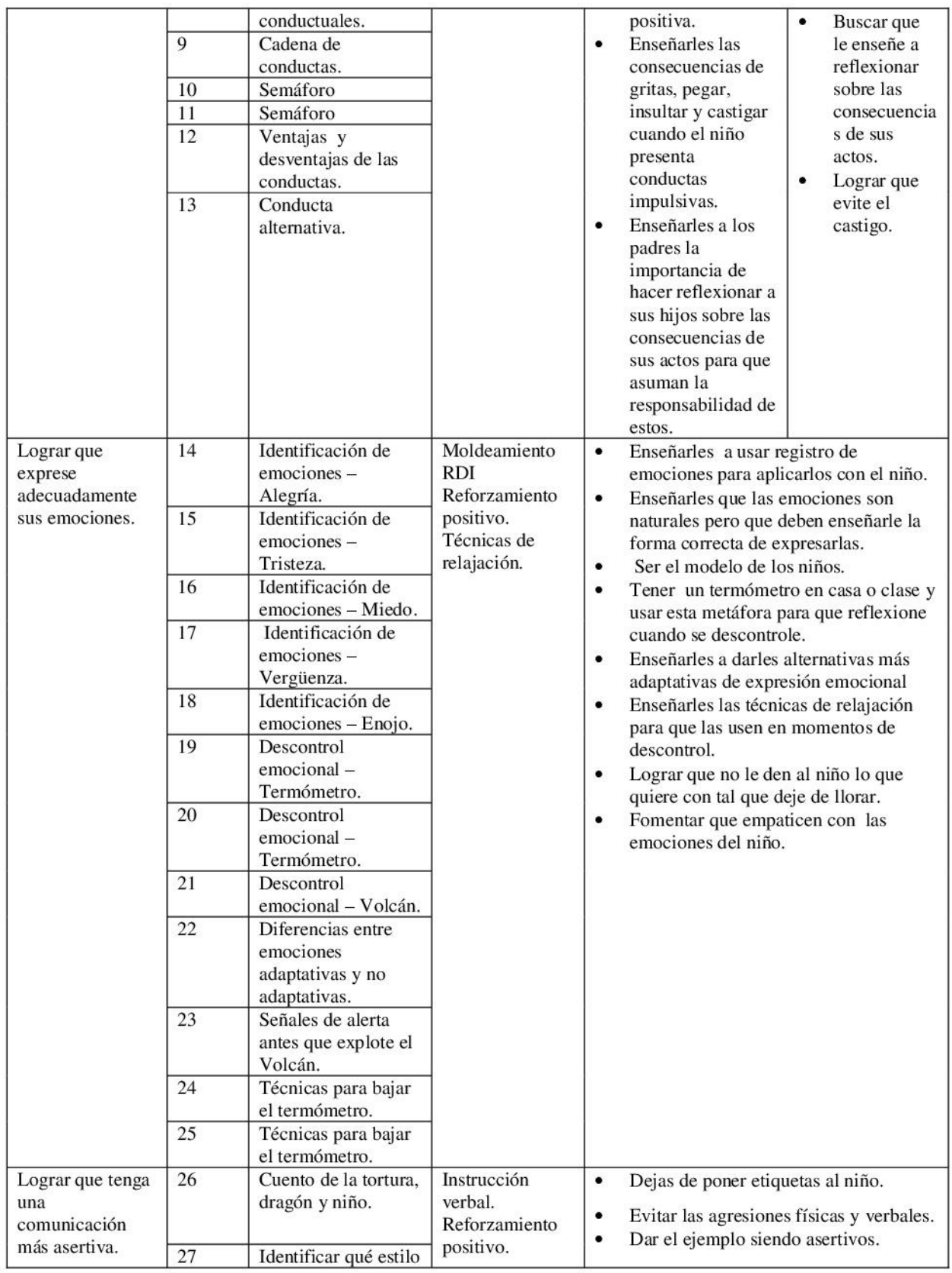




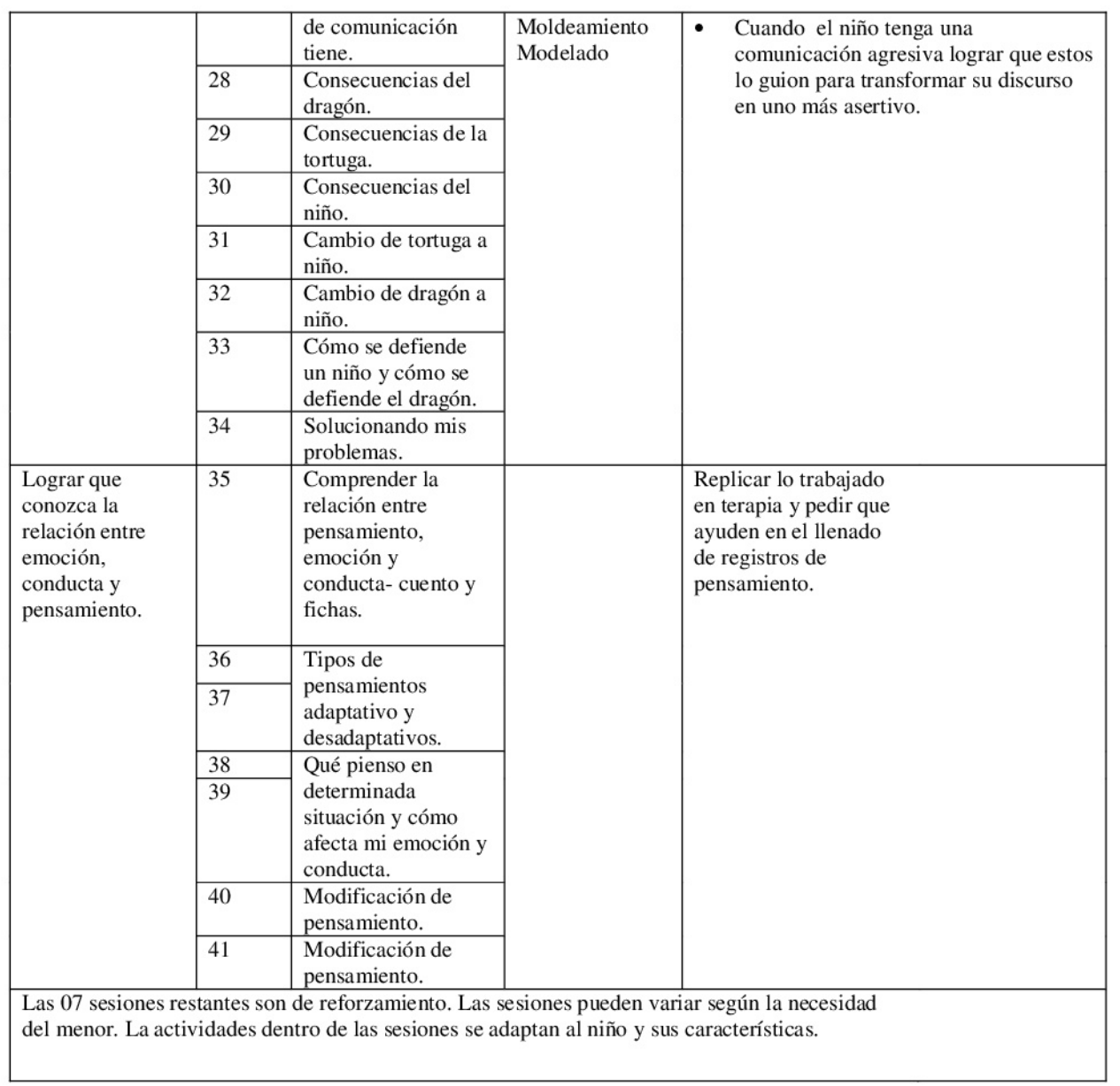


Ejemplo de actividades
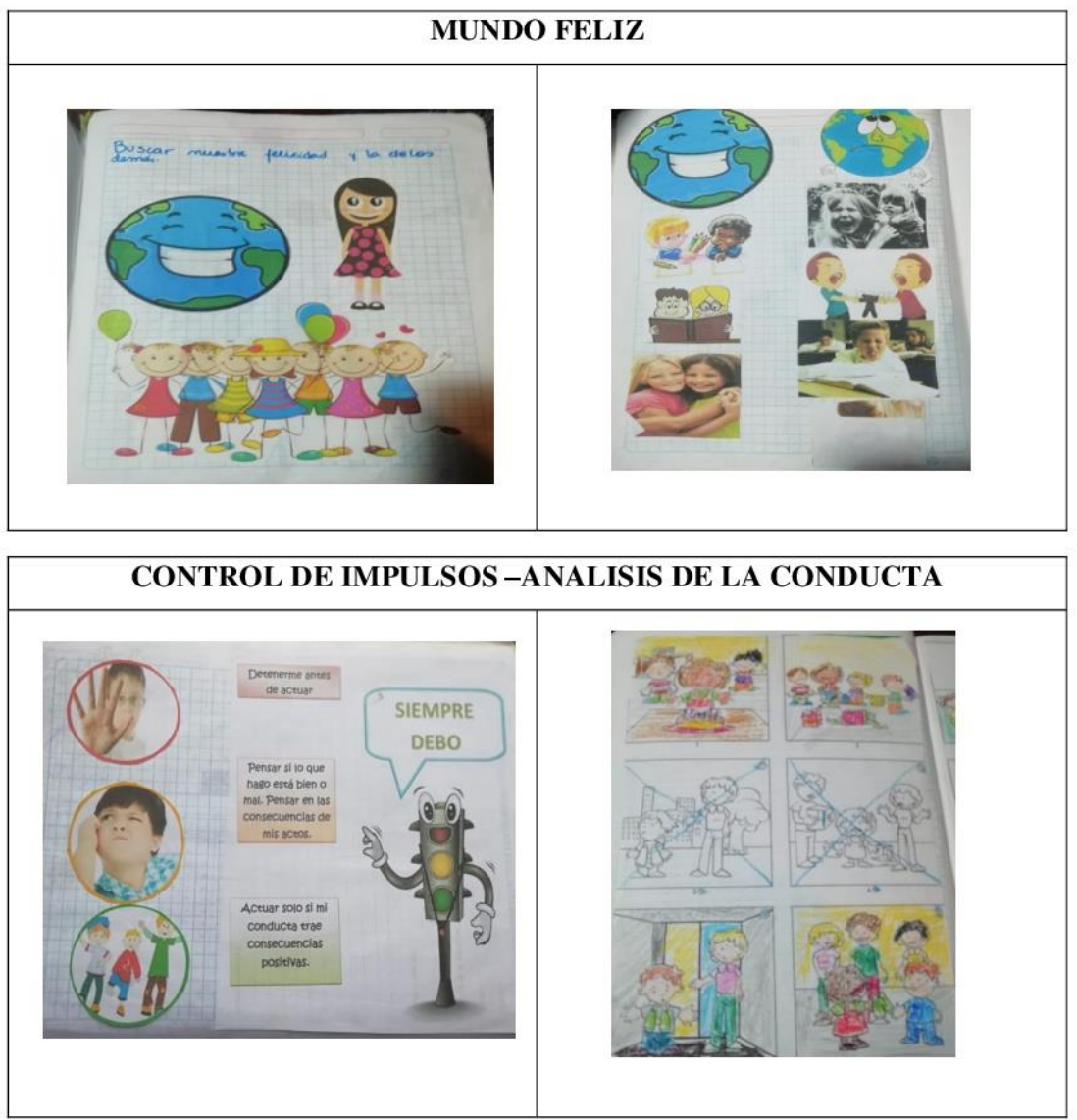


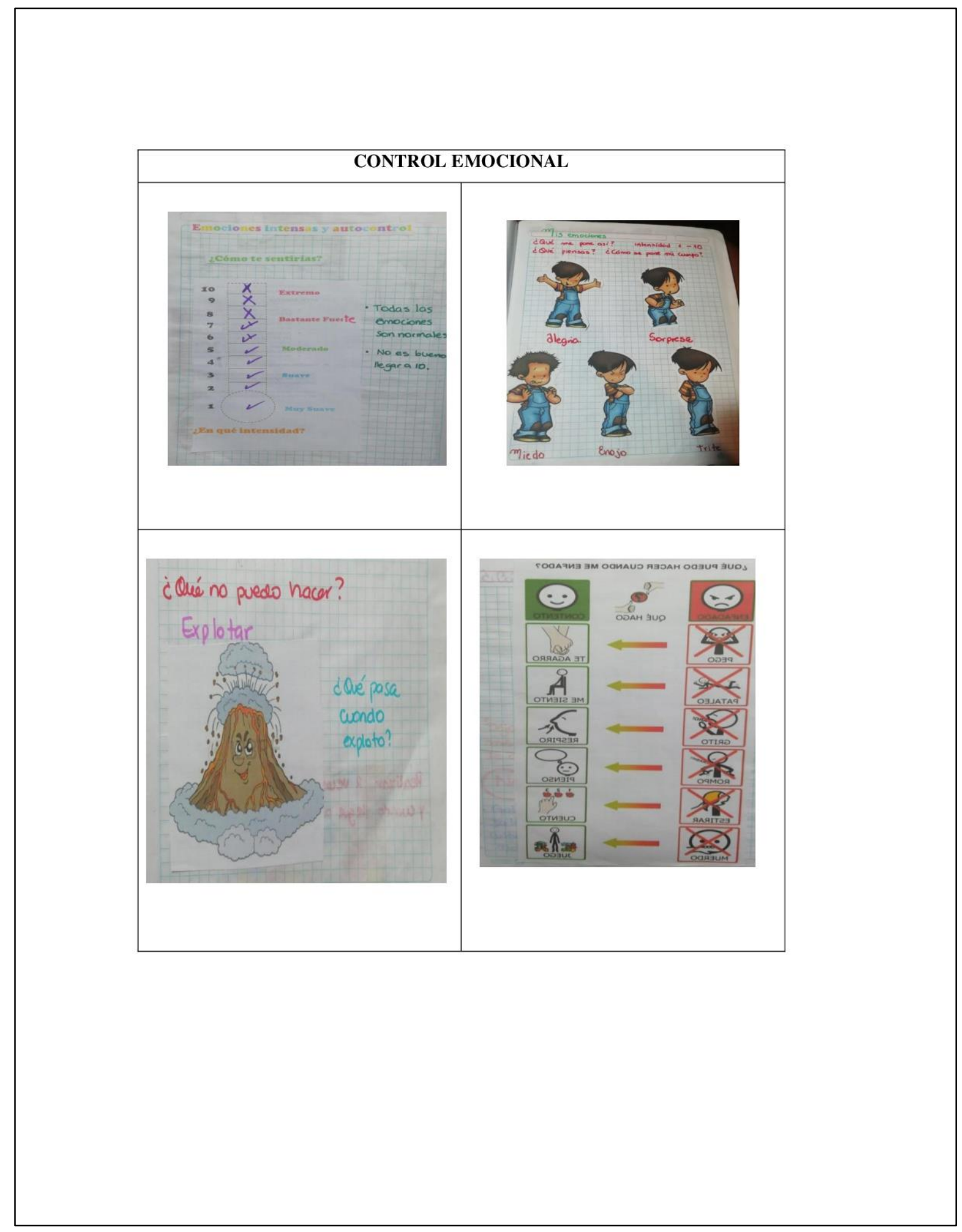




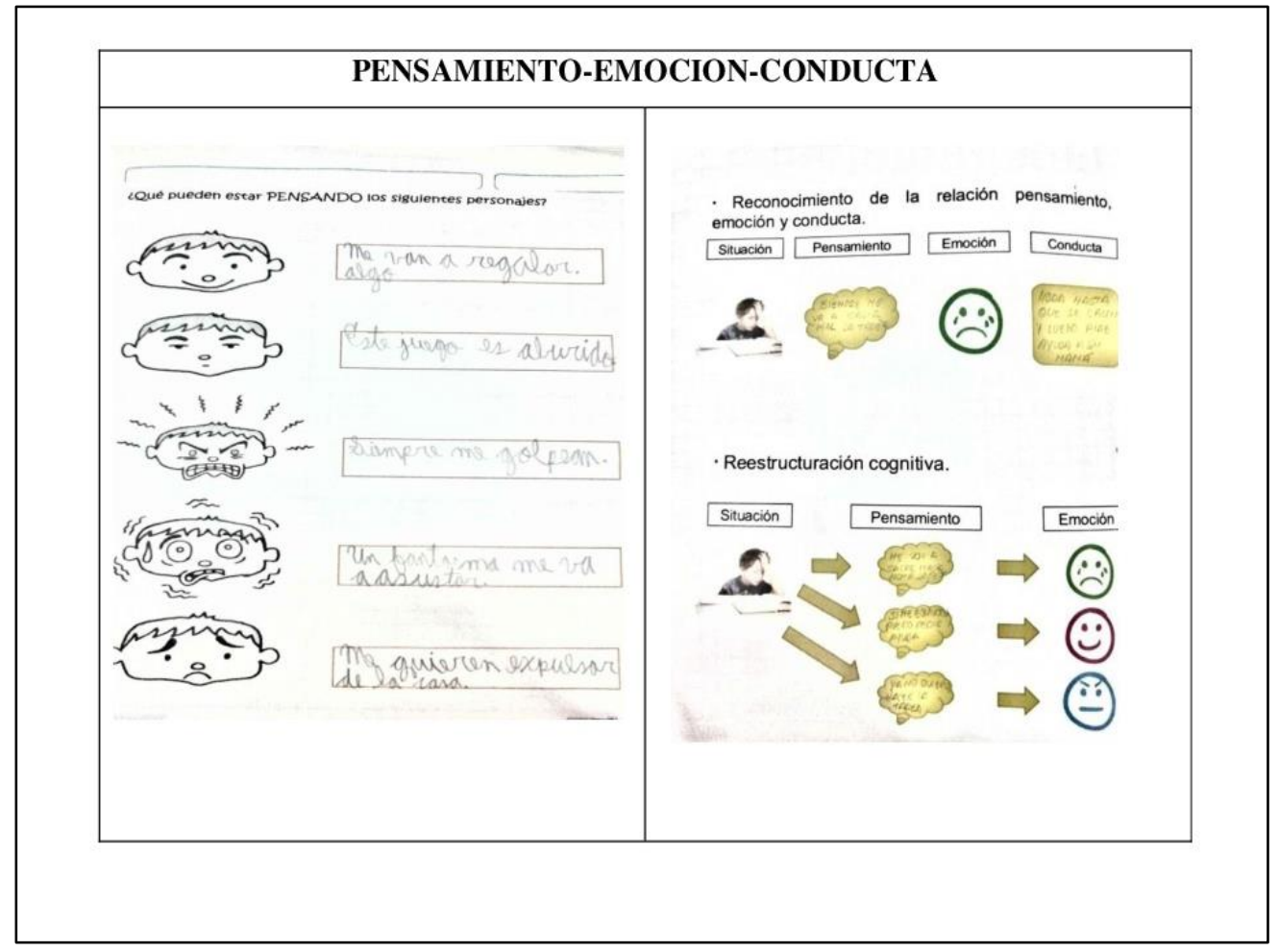

